\title{
reviews:
}

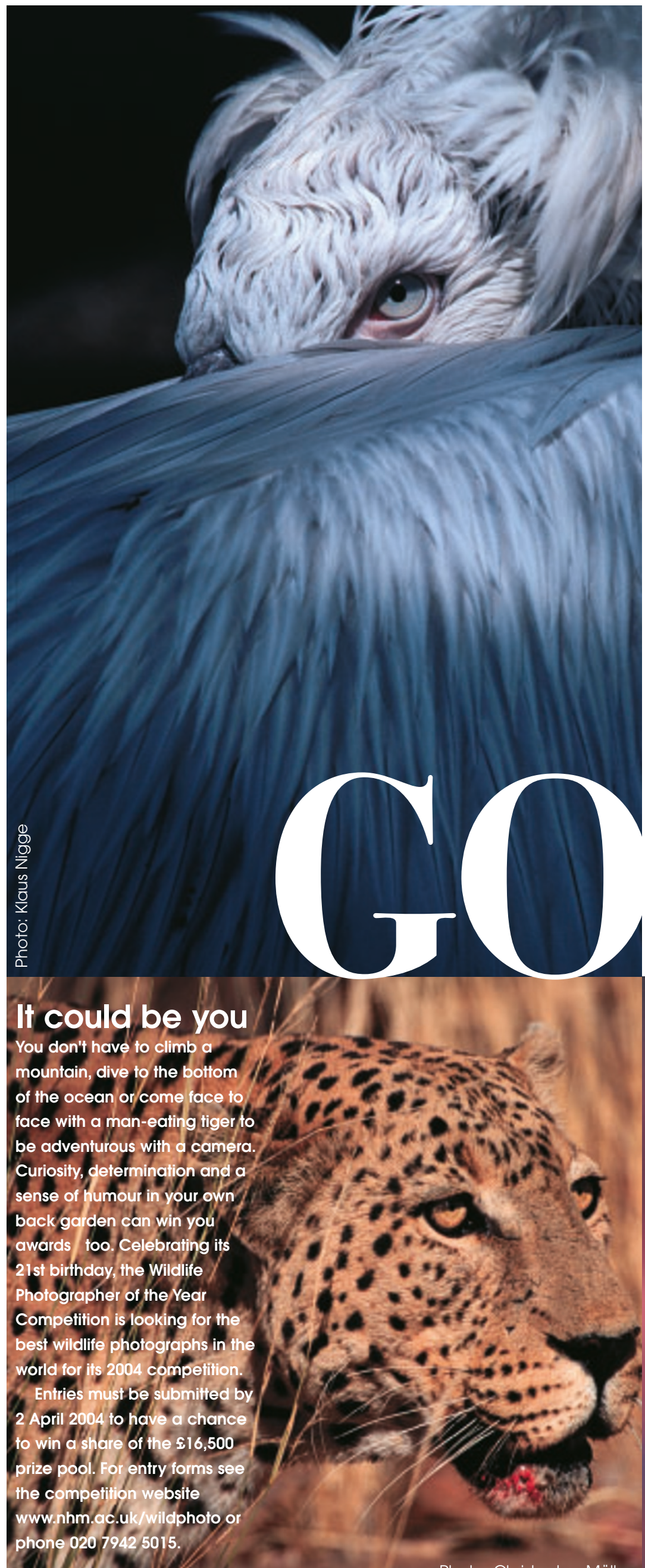

Travel the world with the winners of the 2003 Wildlife Photographer of the Year competition at the Natural History Museum, London.

From the piercing glare of a bald eagle in Alaska to the forlorn gaze of a Texan black-tailed jackrabbit, the images on display in this annual exhibition are at once both haunting and arresting.

The Wildlife Photographer of the Year exhibition, organised by the Natural History Museum and BBC Wildlife Magazine, showcases the best wildlife pictures taken by photographers worldwide, who emphasise through their work the beauty, drama and variety of life on Earth.

The 2003 competition received 20,500 entries from over 60 countries including New Zealand, Mexico, India, Italy and Canada.

What: Wildlife Photographer of the Year 2003 Exhibition
When: Until 18 April 2004.
Where: Natural History Museum, Corner Cromwell
Road and Exhibition Road, South Kensington, London.
Web: www.nhm.ac.uk/wildphoto
How much?: Entry £5.00, £3.00 concessions, £12.00
family, free to under 5s, NHM members and NHM
patrons.
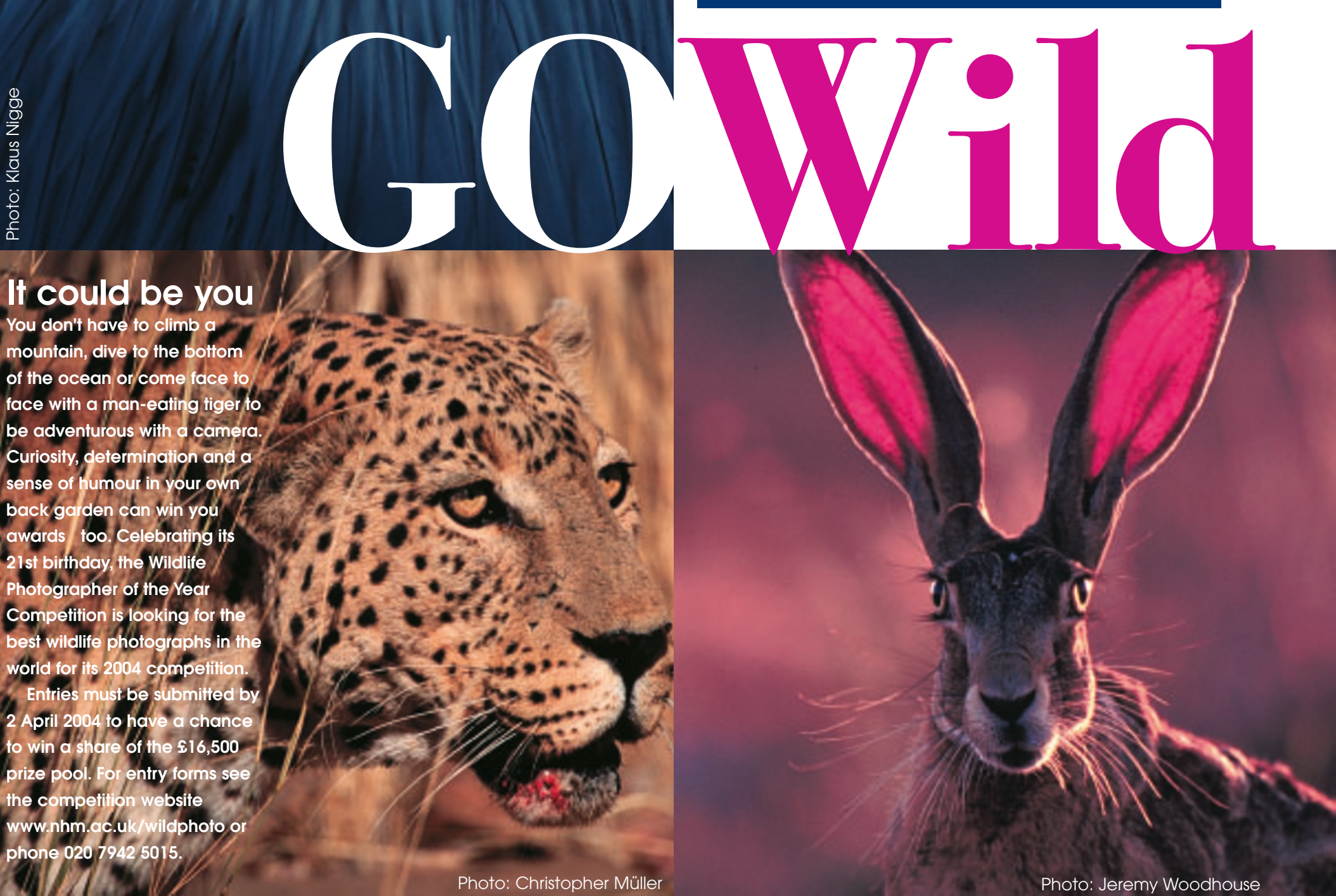

spring 0411 
Vision

Interdental

Perio Brush

Designed to Achieve Effective Cleaning

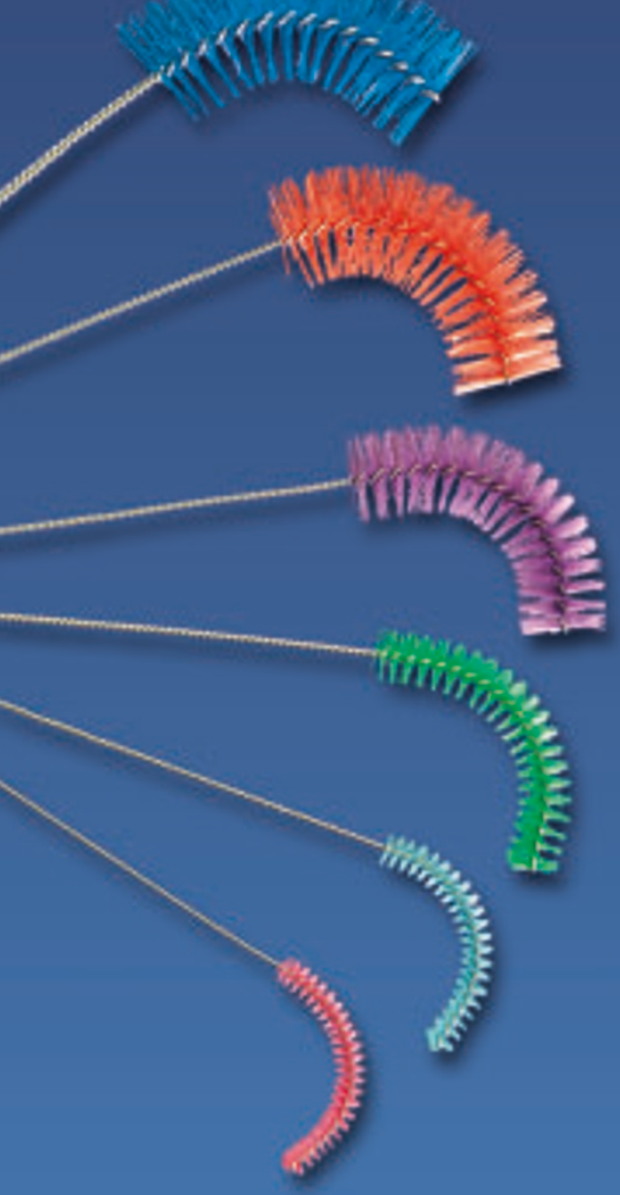

Curved brush head to clean deep into the interdental space

Choice of sizes to achieve a close fit and optimum clean

Coloured filaments to promote use by showing plaque and debris removed

08456345000 www.visionperio.com

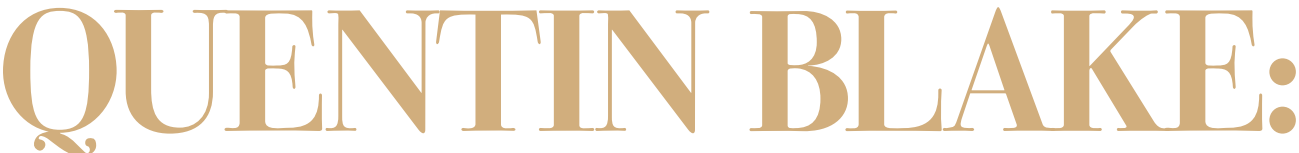

Kate Craig takes a trip down memory lane at the Quentin Blake exhibition at Somerset House.

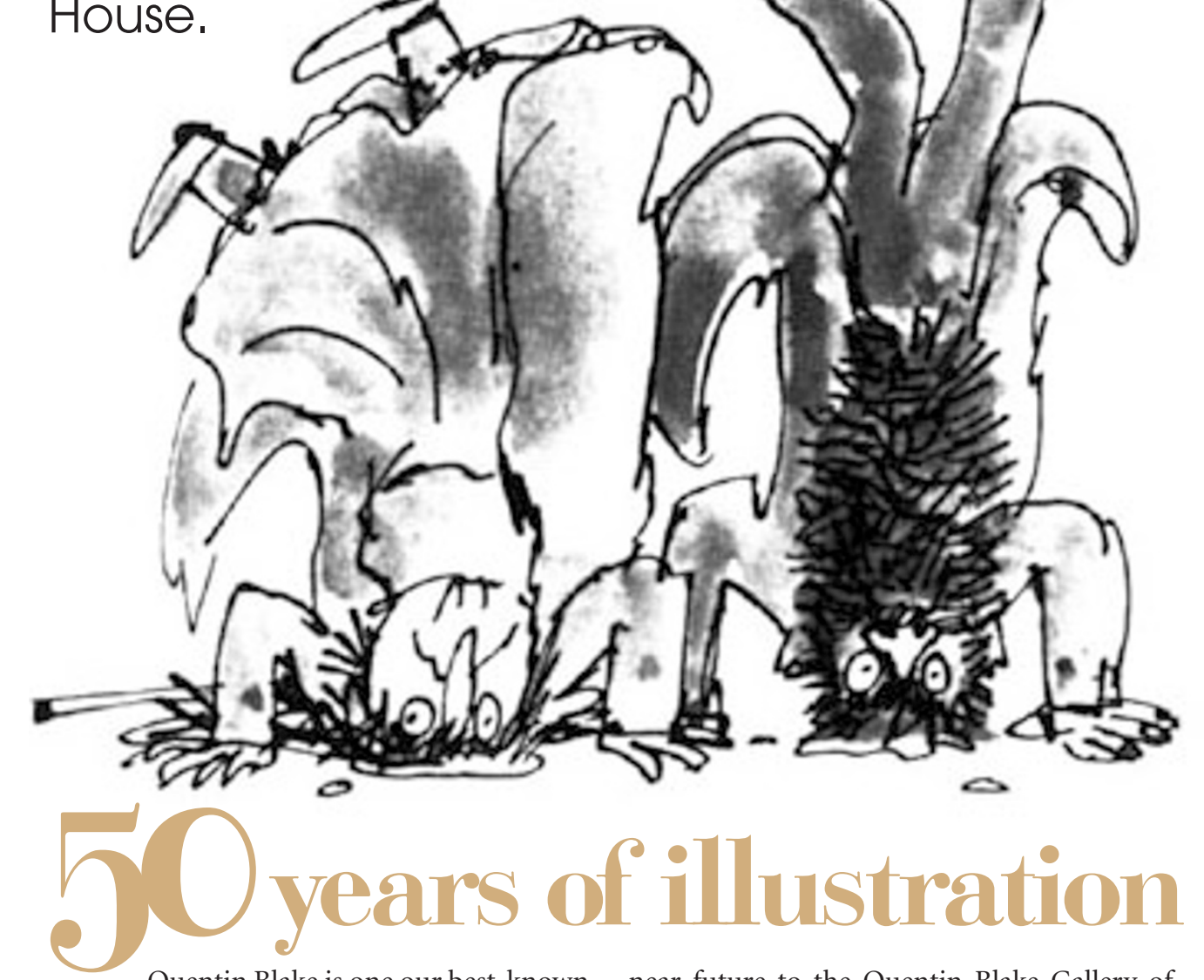

Quentin Blake is one our best-known contemporary illustrators. His career, which has spanned 50 years, has included drawing for Punch and the Spectator, collaborating with writers such as Michael Rosen, Russell Hoban, Joan Aiken and John Yeoman, and more recently creating his picture books. It is his collaboration with writer Road Dahl, however, that he will be forever remembered for.

The Quentin Blake exhibition at the Gilbert Collection, Somerset House, doesn't disappoint. Our old favourites are all in there, from our friend the Big Friendly Giant through to the less friendly Witches and grumpy Mr Twit. I am transported 20 years back in time to Tuesday afternoon storytime at primary school. And it's a place I want to be.

Whole portfolios of roughs, preliminary drawings and finished originals, as well as the final books, give a unique insight into the illustrator's working methods.

The Quentin Blake archive of several thousand original drawings, from which this exhibition is selected, will be handed over in the near future to the Quentin Blake Gallery of Illustration once a suitable site has been found for a permanent home. The gallery will be a flagship centre promoting the art of illustration and its power to communicate and support literature and the arts.

Go and see the exhibition. It's

bound to appeal to the child in all of us.

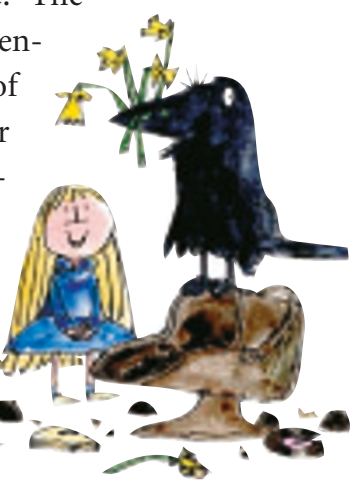

What: Quentin Blake, 50 years of illustration When: Until March 282004

Where: The Gilbert Collection, Somerset House, London WC2R 1LA

Web: www. gillbert-collection.org.uk How much: Included in admission to permanent collection:

Adult: $£ 5.00 \quad$ Over 60s: $£ 4.00$ Under 18, UK full-time students and unemployed: free 


\section{Spotlight on hygienists}

If you are interested in personal development and would like to go on a course to help you in your job or to improve your job prospects, there are lots of courses available. Here is a list of courses and conferences run by various organisations for hygienists both nationally and internationally. Though it is not comprehensive it does includes useful ideas and leads.

The following listing of courses have been supplied by the British Dental Hygienists Association:

\section{Edinburgh Postgraduate Dental Institute - Donna Shaw www.epdi.org.uk/pcd Tel: 01315364970 \\ A variety of one day courses covering implants, fissure sealants, behaviour management, stress management and relaxation, alternative therapies, sedation, assertiveness training.}

\section{Eastman Continuing Professional Development - Ruth Glover www.eastman.ucl.ac.uk/cpd Tel: 02079051239 \\ Back to work and extended duty courses}

\section{Barts \& The London School of Medicine \& Dentistry}

www.smd.qmul.ac.uk/courses/pcd Tel: 02073777634

One year part time course in Oral Health Education

\section{Certificate in Dental Radiography Suffolk College, University of East Anglia Chris Cobb \\ Tel: 01473296606 , \\ www.suffolk.ac.uk/transit/courses/p art-time \\ - University of Keele/Luton Postgraduate Centre Tel: 01582497199 \\ - University of Hertfordshire, Hatfield Tel: 01707 284800/284968 Kent, Surrey and Sussex Dental Deanery \\ Tel: 02074153400 \\ www.kssdeanery.co.uk Extended duties, retaining and returning to work, personal development, first aid and computers in dentistry.}

\section{Extended Duties \& Back to Work Courses}

Gail Vernon

Tel: 01706645240

Email: gailvernon@vsmeurope.com

\section{PCD Training and Education}

Centre, University College of Wales, Cardiff

Tel: 02920744251

www.uwcm.ac.uk/study/dentistry

Short refresher, update and 'return to work' courses for hygienists.

BDHA Regional Groups

Spring Meetings

February - April 2004

www.bdha.org.uk

\section{BDA/BDHA}

Bournemouth International

Conference Centre

8 May 2004

www.bdha.org.uk

British Society of Periodontology

ICC, Birmingham

23-25 May 2004

www.derweb.ac.uk/bsp

16th International Symposium on Dental Hygiene

Madrid, Spain. 8-11 July 2004

www.ifdh.org

Registration: www.siasa.es/online Venue: Palacio de Congresos y

Exposiciones

Theme: Oral Health and

Preventions during the different stages of life

BDHA Annual Scientific and GAM

Edinburgh International

Conference Centre

12-13 November 2004

www.bdha.org.uk

\section{Diary}

2004 BADN Dental Nursing Conference

Date: 08.05.04

Venue: Tralee Hotel, Bournemouth.

Website: www.badn.org.uk/conference

British Dental Conference and Exhibition

Date: 06.05.04-08.05.04

Venue: Bournemouth International Centre

Website: www.bda.org

\section{DTS 2004: Dental Technology Show}

Date: 21.05.04-22.05.04

Venue: International Conference Centre, Telford Website: www.dts2004.com

British Association of Dental Therapists

Annual Scientific Meeting

Date: 11.06.04-12.06.04

Venue: Hilton Leeds City Hotel, Leeds

Website: www.badt.org.uk/events

\section{Book review}

Dental Hygiene Theory \& Practice

Darby \& Walsh, 2nd Edition

What initially looked a daunting prospect proved to be a fascinating project. With over 1,200 pages, this substantial hardback textbook is divided into eight chapters which include pain and anxiety control,

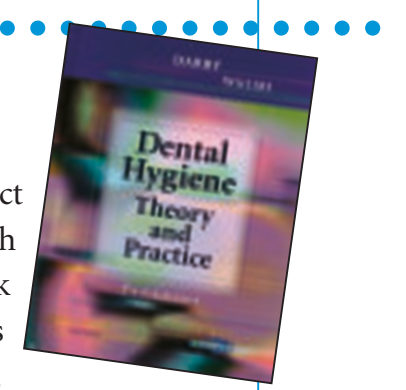
dental hygiene care for individuals with special needs, dental hygiene diagnosis, care plan and evaluation and periodontal and risk assessment.

Convincingly delivered, in a clearly presented and easy to understand format, this textbook is well supported with illustrations, graphs, tables and colour photographs. Each chapter (termed section) starts with its objectives laid out in full with a table of key terminology used in the chapter and ends with a table of 'key concepts' along with a critical thinking exercise. The first chapter begins with an in depth look at historical points of interest in the evolution of dental hygiene and this moves on to concepts of health and wellness. The book discusses communication techniques and improving relationships with patients.

The authors have also developed a website with downloadable resources to support the textbook. It includes a test question bank with over 800 assessment questions, an electronic image collection and competency based evaluation forms which can be used for self-evaluation. Though very Americanised and I think aimed at the American market I found this textbook interesting and informative. Rachel Pointer, BDHA Information Officer. 